\title{
Movimentos sociais na teoria e na prática: como estudar 0 ativismo através da fronteira entre Estado e sociedade?'
}

REBECGA ABERS"

MARISA VON BÜLOW"

\section{Resumo}

Nas últimas duas décadas, os estudiosos dos movimentos sociais passaram a questionar as fronteiras do seu campo de pesquisa. Alguns defenderam a substituição do conceito de "movimentos sociais" por "sociedade civil", enquanto outros propuseram falar de "política do conflito". Em ambos os casos, argumentou-se que o campo de estudos havia se tornado excessivamente limitado, tanto empírica como teoricamente. O artigo discute essas iniciativas e identifica um problema comum: a falta de atenção dada às numerosas formas de interação entre ativistas de movimentos sociais situados dentro e fora do Estado. Argumentamos que a pesquisa empírica que vem sendo realizada no Brasil ajuda a compreender melhor a relação entre Estado e movimentos sociais. Do ponto de vista teórico, é a literatura recente sobre redes sociais que oferece pistas analíticas sobre como pensar no ativismo a partir de dentro das estruturas do Estado.

Palavras-chave: Movimentos sociais. Estado. Participação. Sociedade civil. Política do conflito

1 A ordem dos nomes das autoras é estritamente alfabética, não representando diferenças de participação na elaboração do trabalho, que foi feito em parceria. Agradecemos os comentários feitos por Margaret Keck, Adrian Gurza Lavalle e um parecerista anônimo a uma versão anterior deste trabalho.

* Professora do Instituto de Ciência Política da Universidade de Brasília. E-mail: rebecca. abers@gmail.com

** Professora do Instituto de Ciência Política da Universidade de Brasília. E-mail: vonbulow@ unb.br 


\section{Introdução}

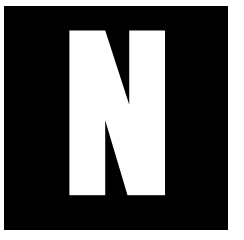

os últimos dez anos, os debates teóricos e metodológicos sobre movimentos sociais passaram por profundas transformações. Para alguns, os anos 2000 abriram uma etapa "pós-paradigmática", que rompeu com os grandes marcos teóricos adotados desde os anos 60 Jasper, 2009). Para outros, a novidade é a tentativa de alcançar sínteses que promovam um maior diálogo entre a literatura de movimentos sociais e discussões mais gerais sobre ação coletiva (Della Porta e Diani, 2006). Uma parte importante desse debate tem tido como foco questões ontológicas básicas, as quais estão relacionadas com a delimitação das fronteiras do objeto de estudo daqueles que se interessam em estudar o que tradicionalmente chamávamos de movimento social.

Essa discussão tem a ver com a própria definição de movimento social. Nas últimas três décadas, os movimentos sociais têm sido compreendidos como uma forma de ação coletiva sustentada, a partir da qual atores que compartilham identidades ou solidariedades enfrentam estruturas sociais ou práticas culturais dominantes ${ }^{2}$. No entanto, o argumento recente de vários autores, que escrevem a partir de marcos teóricos diferentes, é que, ao delimitar nosso estudo a um tipo específico de ação coletiva, tornamos invisíveis formas importantes de organização ou ação social.

Neste artigo, localizamos dois movimentos analíticos que ocorreram na literatura, ambos no sentido de ampliar as fronteiras da nossa unidade de análise: um pôs o foco no papel de uma multiplicidade de organizações da sociedade civil baseadas na solidariedade (substituindo

2 Esta definição genérica é compartilhada por autores associados à literatura dos "novos movimentos sociais", como Touraine (1981, p. 26) e Melucci (1989, p. 57), e também por aqueles ligados à chamada "abordagem do processo político", como Tarrow (2009 [1994], p. 21). 
o termo "movimento social" pelo conceito de sociedade civil), e o outro voltou o olhar para uma ampla gama de processos pautados pelo conflito político (introduzindo o conceito de contentious politics, ou a "política do conflito"). Argumentamos que, apesar de positiva, a tendência atual de incorporação de novos atores e problemas ainda mantém na invisibilidade certos tipos de relações sociais que podem ser importantes para compreender a ação coletiva transformadora.

Mais especificamente, argumentamos que a definição da nossa unidade de análise não deve necessariamente excluir atores que estão posicionados dentro da arena estatal. Na literatura que resenhamos, ora o Estado simplesmente não é - e nem deve ser - relevante, ora é visto como um inimigo, frente ao qual os movimentos sociais ou a sociedade civil têm que medir forças. Até mesmo aqueles que reconhecem que os atores estatais podem ser aliados geralmente não admitem que essas alianças, muitas vezes, envolvem a construção de redes que cruzam as fronteiras entre Estado e sociedade. Em alguns casos, esses vínculos geram ativismo em prol dos movimentos sociais a partir do próprio Estado. Para dar conta desses fenômenos, propomos que as fronteiras organizacionais da nossa unidade de análise não deveriam ser definidas a priori, mas sim pelo formato das redes de ação coletiva que existem na prática.

Na primeira parte do texto, apresentamos uma síntese das duas propostas anteriormente mencionadas, restringindo-nos às visões de alguns dos seus principais autores. Em vez de apresentar essas contribuições de forma completa, focamos a discussão na maneira como as relações entre sociedade e Estado são compreendidas. Em seguida, com base principalmente no caso do Brasil, apresentamos vários exemplos de intersecções entre movimentos sociais e Estado. Sugerimos que esses exemplos colocam em xeque tanto o pressuposto de que o Estado é irrelevante como o pressuposto de que atores estatais são necessariamente externos aos movimentos sociais. Na seção seguinte, propomos que a literatura que 
discute movimentos sociais a partir da ótica de redes possibilita compreender ativistas dentro do Estado não apenas como interlocutores amigos, e sim como parte da nossa unidade de análise. Terminamos o artigo apresentando uma proposta de agenda de pesquisa e refletindo sobre as implicações, para os estudiosos de movimentos sociais, da impossibilidade de separar de forma rígida Estado e sociedade civil.

\section{Dos Novos Movimentos Sociais à Sociedade Civil}

A primeira proposta de ampliação do campo de estudos dos movimentos sociais aqui resenhada aflorou ainda nos anos 90 e teve origem na literatura dos "novos movimentos sociais", a qual, nas décadas anteriores, havia se dedicado à análise de transformações nas estruturas sociais e ao papel social de novos sujeitos sociais (Della Porta e Diani, 2006, pp. 8-11) ${ }^{3}$. Sob a influência do pensamento habermasiano, apareceu uma literatura sobre a importância política da vasta arena que se situa fora do Estado e fora do mercado, na qual existiriam (ou deveriam existir) teias interligadas de grupos e associações engajadas em práticas comunicativas caracterizadas pelo respeito mútuo e pela solidariedade.

Como argumenta Alonso (2009), especialmente depois da publicação do livro Civil Society and Political Theory, por Cohen e Arato (1992), o termo "novos movimentos sociais" foi sendo substituído pela noção mais ampla de "sociedade civil". A Teoria dos Novos Movimentos Sociais "deixou,

3 Enquanto os "velhos movimentos sociais" se preocupavam fundamentalmente com redistribuição, relações capital-trabalho e controle sobre o Estado, os "novos movimentos sociais" se dedicavam à afirmação de identidades, "definições da boa vida" (Habermas, 1987, p. 33 apud Alonso, 2009, p. 62) e "inovação cultural" (Melucci, 1989, p. 61). Além disso, supostamente se caracterizavam pelo seu desinteresse em tomar o poder do Estado. Esses autores caracterizaram os movimentos sociais como promotores de mudanças "dentro da sociedade", mais do que especificamente tendo como objetivo influenciar a ação do Estado por meio da defesa ou contestação de leis ou políticas públicas. 
então, de associar a inovação a um ator, os movimentos, para atrelá-la a um lócus, a sociedade civil" (Alonso, 2009, p. 75). Há dois aspectos importantes a serem enfatizados nessa mudança. Em primeiro lugar, os autores já não focam mais em movimentos sociais específicos. Em vez disso, falam de uma multiplicidade de atores e organizações, caracterizados não tanto pela sua temática (meio ambiente, juventude, feminismo, etc.), mas sim pela sua luta comum por criar um espaço de liberdade comunicativa. A transição de "novo movimento social" para "sociedade civil" envolveu, portanto, uma ampliação da unidade de análise, para incluir uma coleção muito mais diversificada de organizações e grupos. Como Habermas colocou a questão,

O (...) núcleo central [da sociedade civil] é formado por associações e organizações livres, não estatais e não econômicas, as quais ancoram as estruturas de comunicação da esfera pública nos componentes sociais do mundo da vida. A sociedade civil compõe-se de movimentos, organizações e associações, os quais captam os ecos dos problemas sociais que ressoam nas esferas privadas... (Habermas, 2003, p. 99).

Um argumento importante que surge dessa literatura - pelo menos dos autores que se inspiraram nos trabalhos de Habermas e de Cohen e Arato - é que a sociedade civil, à medida que é exitosa, opera fora das esferas de influência do Estado e do mercado. A noção de uma sociedade civil "autolimitada", muito enfatizada por Cohen e Arato (1992), se refere à ideia de que os atores da sociedade civil constituem um campo separado que precisa manter sua distância tanto do mercado como do Estado, para poder garantir a comunicação livre e o respeito mútuo. Mecanismos de influência entre esfera pública e Estado devem existir, mas sem ameaçar a autonomia da esfera pública ${ }^{4}$.

4 Um objetivo central do livro Direito e Democracia de Habermas é rebater as críticas de que a sua tese de autonomia da esfera pública a tornaria incapaz de influenciar o Estado, sendo, portanto, irrelevante. Habermas argumenta, essencialmente, que esta influência deveria ocorrer à distância, "por meio da atividade dos partidos políticos e da participação eleitoral dos cidadãos" (2003, p. 101). 
A autolimitação é vista como necessária para que associações e grupos na sociedade civil possam se caracterizar como esfera pública, definida por Habermas como o espaço social "que se alimenta da liberdade comunicativa que uns concedem aos outros" (Habermas, 2003, p. 93). Na esfera pública, a sociedade civil se constituiria como palco para a tematização de problemas sociais e de produção livre da vontade e opinião pública, peça fundamental para a construção de uma verdadeira soberania popular. Mas isso só poderá ocorrer se indivíduos tiverem a liberdade comunicativa de discutir problemas sociais e políticos sem a interferência de desigualdades econômicas, diferenças de status social, ou hierarquias políticas e sociais. Em tal situação, diz Habermas, a única forma de poder que prevalece seria o "poder do melhor argumento" (Habermas, 1984, p. 25). Por outro lado, à medida que as associações e os grupos da esfera pública forem contaminados pela lógica concorrencial do mercado ou pelo poder hierárquico do Estado, a liberdade comunicativa seria prejudicada. ${ }^{5}$

É importante frisar, como fazem Arato e Cohen (1994), que o argumento não é que todas as organizações não governamentais e não lucrativas são dominadas por relações de solidariedade, igualdade ou cooperação. Pelo contrário, a grande preocupação desses autores é com a "colonização" da sociedade civil pela lógica do poder administrativo e da competição por lucros, impedindo sua formação como espaço-chave no qual os indivíduos possam desenvolver livremente suas opiniões sobre os problemas da sociedade.

Grande parte das críticas ao conceito normativo de sociedade civil apresentado por Cohen, Arato e Habermas ressalta que este não refletiria a realidade do mundo associativo. Alguns (e.g. Chambers, 2002) enfatizam a existência de bad civil society, ou seja, de grupos que se organizam

5 É interessante notar que a visão habermasiana não é a única a associar sociedade civil com liberdade comunicativa. Em especial, Michael Walzer descreve a sociedade civil como um espaço "of people freely associating and communicating with one another" (Walzer, 1998, p. 7). 
em torno de ideias intolerantes ou para defender interesses particularistas. Mais do que somente um erro empírico, afirma Neera Chandoke, a idealização da sociedade civil é perigosa para nossa capacidade de entender o papel das associações na vida política:

Can we assume that civil society possesses a distinct logic of its own, which is in sharp contrast to that of the state or the market? Can we correspondingly assume that it is quite as autonomous of other spheres as much as we would like it to be? ....our normative expectations about the sphere of civil society should not derange our analysis of actually existing civil societies. (Chandoke, 2001, p. 5)

Nesse sentido, a principal crítica ao conceito de sociedade civil foca na ideia de que poderia existir uma esfera social separada, distante do Estado e do mercado, na qual comportamentos como reciprocidade e respeito mútuo predominariam.

Além desse tipo de crítica da validade "empírica" do conceito, alguns autores sugerem que valorizar somente aqueles grupos que atuam longe do mercado e do Estado e nos quais predominam relações não conflituosas é inadequado a partir de uma perspectiva normativa. Mark Warren, por exemplo, discute as contribuições para a democracia de diferentes tipos de associações. Para esse autor, focar apenas naquelas caracterizadas por relações de solidariedade e reciprocidade não é útil:

For problems of democracy, the associational kinds that mediate between 'pure' associations, states, and markets are often the most interesting. Mediating forms of association - political parties, unions, and consumer cooperatives, for example -- ... serve as the conduits through which associative relations can potentially affect markets (Warren, 2001, p. 58)

O comentário de Warren levanta uma questão importante: da maneira como o conceito de "sociedade civil" tem sido utilizado pelos autores resenhados anteriormente exclui determinados tipos de organizações cívicas que são fundamentais no funcionamento da democracia, especial- 
mente no sentido de mediar entre Estado, mercado e componentes mais "isolados" da sociedade civil. Desse modo, nas críticas feitas, Warren e Chandoke trazem uma preocupação que aparece, como veremos mais adiante, em boa parte da literatura brasileira e latino-americana sobre sociedade civil: a rejeição cada vez maior de perspectivas que insistem que movimentos sociais se mantenham sempre distantes do Estado.

\section{Dos Movimentos Sociais à Política do Conflito}

Apesar da grande importância adquirida pela literatura sobre a sociedade civil na última década, nem todos os estudiosos dos movimentos sociais adotaram esse conceito e nem a consequente ênfase analítica na separação entre Estado e sociedade civil. Outro grupo de pesquisadores, em sua maioria associados à chamada "abordagem do processo político", abriu um debate ao longo dos anos 90, que, se bem também propunha uma ampliação das fronteiras do campo de estudos, procurou enfatizar o conflito, em vez da reciprocidade e da comunicação, como guia para essa ampliação. Neste artigo, tomaremos o livro Dynamics of Contention (DOC), publicado por Doug McAdam, Sidney Tarrow e Charles Tilly em 2001, e os debates que o sucederam como nossas principais referências.

Assim como a literatura sobre "sociedade civil", os autores de DOC também criticaram o olhar empírico limitado dos estudos sobre movimentos sociais das décadas anteriores. Em especial, se declararam insatisfeitos com a compartimentalização dos estudos sobre greves, guerras, revoluções e movimentos sociais, e argumentaram que poderíamos aprender mais sobre esses fenômenos ao estudá-los em conjunto, em vez de separadamente (DOC, p. 4) ${ }^{6}$. Esse diagnóstico sobre a literatura existente, feito

6 Os autores de DOC partiram do pressuposto de que, ao longo da década de 1980, a maior parte dos estudiosos dos movimentos sociais passou a adotar uma agenda teórica comum, que se diferenciava apenas em termos da ênfase dada a um mesmo conjunto de variáveis para explicar o surgimento (ou não) de movimentos sociais. Essa agenda comum foi denominada 
em parte a partir de uma crítica aos seus próprios trabalhos anteriores, levou os autores a proporem um redimensionamento dos estudos sobre ação coletiva, que privilegiasse o olhar sobre o que denominaram de contentious politics - a "política do conflito" -, definida como:

episodic, public, collective interaction among makers of claims and their objects when (a) at least one government is a claimant, an object of claims, or a party to the claims and (b) the claims would, if realized, affect the interests of at least one of the claimants (Ibid, p. 5).

Os casos de interação coletiva conflituosa incluídos nessa definição podem ser "contidos" quando todos os participantes são atores previamente estabelecidos, que empregam meios amplamente conhecidos para apresentar suas demandas, ou "transgressores", quando pelo menos alguns atores são novos e, em parte, utilizam meios de ação coletiva inovadores ou proibidos (Ibid, p. 7-8). O livro opta por concentrar-se no estudo dessa segunda forma de interação. Assim, a mudança da lente empírica utilizada não se refere tanto ao tipo de ator envolvido (sindicato, ONG, movimento nacionalista ou associação de moradores, por exemplo), mas sim ao tipo de ação que promovem, ou seja, os meios empregados e o nível de institucionalização dos atores no sistema político. A partir desta nova proposta de delimitação do objeto de estudo, os autores oferecem uma análise de

pelos autores de DOC como o "modelo clássico" de estudos dos movimentos sociais. Como parte da justificativa para abandonar esse modelo de teorização em favor de um modelo baseado no "conflito político", McAdam, Tarrow e Tilly argumentaram que o primeiro oferecia apenas explicações parciais para movimentos sociais localizados na Europa e nos Estados Unidos. Não seria um guia adequado para explicar a grande variedade de formas de política contenciosa fora do marco dos Estados ocidentais democráticos (DOC, pp. 18-19). Os autores de DOC também denunciaram o caráter supostamente estático e demasiado estruturalista do "modelo clássico". Nessa visão, as diferentes variáveis - como a existência de recursos ou oportunidades - teriam passado a servir como uma caixa de ferramentas que os pesquisadores utilizariam, de forma mecânica, para explicar o surgimento de movimentos sociais, sem efetivamente conseguir explicar o vínculo entre essas variáveis e os processos de mobilização. 
15 importantes episódios de conflito, que vão desde a Revolução Francesa e o movimento pelos direitos civis nos Estados Unidos até processos de democratização e movimentos nacionalistas em países em desenvolvimento.

A análise dessa diversidade de episódios é feita pelos autores de DOC a partir da identificação de mecanismos e processos similares. Mecanismos são definidos como "a delimited class of events that alter relations among specified sets of elements in identical or closely similar ways over a variety of situations" (Ibid, p.24). Processos, por sua vez, são "regular sequences of such mechanisms that produce similar (generally more complex and contingent) transformations of those elements" (idem). A opção por tentar identificar mecanismos e processos em uma grande variedade de casos de conflito político serviria como antídoto para uma visão dos movimentos sociais que, além de empiricamente restrita, teria se tornado estática e determinista. Por exemplo, em vez de falarmos sobre a existência de "oportunidades políticas" como fatores estruturais objetivos que explicariam a emergência de movimentos sociais, passaríamos a ter que analisar o mecanismo de "atribuição de oportunidades políticas"7. Em vez de apontarmos para recursos preexistentes, passaríamos a buscar compreender o mecanismo de "apropriação social" desses recursos (ibid, p. 43-48).

Ao longo dos quase dez anos desde que DOC foi publicado, o programa proposto foi debatido e criticado exaustivamente em livros e periódicos, especialmente por pesquisadores norte-americanos e europeus ${ }^{8}$.

7 Não existe, portanto, uma estrutura de oportunidades políticas objetiva, a partir da qual todos os movimentos sociais reagiriam de forma similar, mas sim uma interpretação das mudanças no contexto da ação (DOC, pp. 46-47). Essa ênfase no caráter dinâmico e potencialmente diverso da atribuição de oportunidades também foi feita anteriormente por autores que criticaram o uso excessivamente estruturalista do conceito na literatura dos movimentos sociais. Ver, por exemplo, Goodwin e Jasper 1999.

8 Os críticos se dividiram entre aqueles que concordaram, de forma geral, com o diagnóstico do campo apresentado (Koopmans, 2003; Oliver, 2003), os que concordaram parcialmente (Diani 2003) e aqueles que negaram a existência de "um" modelo "clássico" com o qual seria necessário romper (Rucht 2003). Para este último grupo, a simplificação da literatura anterior serviria como um "espantalho" conveniente, mas que não faria justiça à heterogeneidade do 
Para os fins deste artigo, o que interessa é analisar como os autores definiram as relações entre os atores transgressores e o Estado. Ao contrário da literatura sobre sociedade civil, o Estado tem um papel central no modelo proposto. De fato, os exemplos empíricos utilizados no livro se referem fundamentalmente a casos nos quais "national states were direct participants or significant parties to the claims being made" (ibid, p. 8). Entretanto, a localização teórica dos atores na intersecção entre política e conflito reduziu o alcance da análise que poderíamos fazer sobre o papel do Estado em três sentidos.

Em primeiro lugar, os autores de DOC excluíram da sua agenda de estudos aqueles movimentos que não têm Estados como interlocutores (Rucht, 2003, p. 113; Taylor, 2003, p. 124). Ficaram de fora, por exemplo, as lutas entre movimentos sociais, assim como as ações coletivas que não envolvem necessariamente o Estado, como aquelas que questionam códigos culturais e padrões de consumo. Em outras palavras, os autores promoveram uma visão demasiado estreita da política, vista fundamentalmente em termos da relação com governos. Em segundo lugar, a definição proposta reduz de forma exagerada o alcance da análise. Apesar de admitirem prontamente que nem toda política é necessariamente conflituosa (DOC, p. 5), na prática a ênfase na luta e no conflito levou à exclusão de outras formas importantes de ação coletiva, como, por exemplo, as "comunidades intencionais", tais como ecovilas e movimentos de economia solidária, nas quais as pessoas se reúnem não para desenvolver conflitos, mas para viver em torno de princípios sociais e ambientais alternativos (Schehr, 1997; Lisboa, 2003), e as várias formas de intersecção entre ativistas de movimentos sociais e atores estatais que analisamos a seguir.

campo (Idem, p. 113). Outros lembraram que várias das críticas formuladas em DOC, em especial a crítica da visão estática e superestruturalista de muitos estudos, já haviam sido feitas anteriormente por alguns estudiosos dos movimentos sociais, como, por exemplo, Alberto Melucci (e.g., Diani 2003). 
O vínculo analítico entre Estado e conflito foi defendido mais claramente por Doug McAdam, ao responder aos críticos de DOC:

As political analysts concerned with understanding how the potential for significant social change could be realized through struggle, we feared the absence of significant analytic/empirical attention to states and other institutional authorities was creating a Ptolemaic perspective, with movements as the distorted center of the political universe. How, we reasoned, could one ever hope to understand the political significance of movements without taking seriously the broader institutional context and set of actors that movements confront to make change? (McAdam, 2003, p. 127)

Ao vincular mudança social e luta política, McAdam deixa claro que a relação entre movimentos sociais e Estados deve ser vista a partir da ótica do conflito. Em obra publicada posteriormente por Tilly e Tarrow, os autores admitem que muitos processos conflitivos não incluem governos. Contudo, argumentam que, mesmo nesses casos, muitas vezes há algum tipo de contato com o governo (Tilly e Tarrow 2007, p. 6). Mantêm, portanto, a proposta de focar em fenômenos de política do conflito tal como os marcos desse objeto de estudo foram definidos em 2001. Assim, ao mesmo tempo em que trazem o Estado (na realidade, o governo) para o centro do debate, continuam excluindo análises que tenham como objetivo compreender como ativistas e aliados interagem dentro do Estado.

Há ainda um terceiro sentido - talvez o mais controverso - a partir do qual o modelo proposto em DOC restringe a nossa compreensão das relações entre movimentos sociais e Estado. Independentemente de se o Estado é visto como aliado ou inimigo, quase todas as abordagens sobre movimentos sociais - incluindo não apenas a abordagem do processo político e da política do conflito, mas também a literatura sobre sociedade civil - presumem que os movimentos podem ser definidos como sendo inerentemente distintos do Estado. Ou seja, Estados ou governos - geral- 
mente definidos de forma vaga - operam essencialmente fora do espaço organizativo dos movimentos. Em outras palavras, os ativistas interagem com o Estado, mas não participam diretamente da gestão estatal.

Esse pressuposto impede que se capturem algumas das relações complexas que existem entre pessoas no aparato estatal e aquelas que agem a partir de organizações de movimentos sociais. Se pensarmos o Estado como um bloco homogêneo que opera em um espaço organizativo distinto, dificilmente conseguiremos reconhecer redes que cruzam as fronteiras entre Estado e sociedade civil como parte importante dos movimentos sociais. Porém, como sugerimos a seguir, na América Latina - e, em particular, no Brasil - as redes de movimentos sociais muitas vezes cruzam essas fronteiras.

\section{Movimentos Sociais no Brasil: esbarrando no Estado}

$\mathrm{Na}$ introdução ao livro States, parties, and social movements, publicado em 2003, Jack Goldstone chama a atenção para a necessidade de aprofundar os estudos sobre as relações entre formas institucionalizadas e não institucionalizadas de fazer política. Seu argumento para justificar essa necessidade é que "state institutions and parties are interpenetrated by social movements, often developing out of movements, in response to movements, or in close associations with movements" (p. 2). Os capítulos publicados nessa obra efetivamente mostram como, em vários países e regiões do mundo, tem se tornado cada vez mais difícil compreender os movimentos sociais sem fazer uma análise dos vínculos com partidos políticos e o Estado, e vice-versa, como é importante incorporar o estudo dos impactos da ação de partidos políticos e órgãos estatais nos movimentos sociais.

Neste artigo, nos baseamos na literatura brasileira recente sobre movimentos sociais para mostrar como a distinção entre ativista em movi- 
mentos sociais e ator estatal pode ser pouco clara. Os movimentos sociais têm lutado tanto para transformar comportamentos sociais como para influenciar políticas públicas. Como parte desses esforços, muitas vezes se mobilizam em prol de mudanças nos processos de tomada de decisão estatal, demandando a inclusão da sociedade civil em novos espaços participativos. Essa demanda implica não somente na criação de espaços de diálogo entre atores da sociedade civil e do governo, mas da maior presença de ativistas de movimentos sociais dentro do próprio Estado.

O envolvimento de movimentos sociais em esforços por democratizar o Estado tem sido importante na América Latina pelo menos desde o início dos anos 80. Nos últimos anos, grande parte da literatura sobre sociedade civil tem procurado analisar a participação de ativistas em arenas de formulação e implementação de políticas públicas, tais como o orçamento participativo e conselhos gestores. Esse processo de construção de novas arenas participativas tem sido, especialmente no Brasil, um processo intenso de aproximação entre atores sociais e estatais. No entanto, as relações entre movimentos sociais e Estado frequentemente extrapolam esses encontros em espaços decisórios formais ${ }^{9}$. Nossa revisão da literatura sobre movimentos sociais brasileiros permitiu detectar pelo menos dois padrões adicionais de intersecção entre movimentos sociais e o Estado ao longo das duas últimas décadas: a incorporação de ativistas de movimentos sociais em cargos governamentais e a formação de novos movimentos sociais a partir da interlocução entre ativistas dentro e fora do Estado. Em especial, essa literatura tem se dedicado a estudar especificamente as imbricações entre movimentos sociais e o Poder Executivo.

9 É importante também notar que tais espaços muitas vezes não se limitam a debates e deliberações. Como Abers e Keck (2009) argumentam, atores da sociedade civil frequentemente se empenham na tentativa de fortalecer capacidades estatais e de garantir a execução de decisões. 
No contexto de um crescente interesse na democracia e na participação em processos decisórios, os ativistas, frequentemente, cruzam a fronteira entre o Estado e a sociedade, trabalhando em alguns momentos em organizações da sociedade civil e em outros momentos em órgãos estatais. Essa tem sido uma tendência em uma variedade de tipos de movimentos sociais, e tem sido notada e analisada na literatura latino-americana. No entanto, participar ou não nessas arenas oficiais tem sido um tema extremamente polêmico. Enquanto alguns movimentos sociais têm rejeitado sistematicamente essa possibilidade, outros movimentos sociais têm tentado utilizar o Estado como plataforma a partir da qual dar maior visibilidade e eficácia às suas demandas.

Por exemplo, na sua análise sobre o feminismo latino-americano da década de 1990, Sonia Alvarez argumenta que, nesse período, tornou-se prática comum nos governos da região a criação de novas agências dedicadas às questões da mulher. Um resultado disso é que feministas proeminentes acabaram ocupando posições nas burocracias estatais. Para Alvarez, esse não é necessariamente um sinal de cooptação ou de perda de autonomia. A autora cita a pesquisa de Amy Lind sobre feministas em posições burocráticas no Equador, argumentando que "feministas que atuam dentro do Estado ou de instituições tradicionalmente dominadas pelos homens da sociedade civil e política estão também engajadas em lutas pelo 'poder interpretativo' na definição do domínio discursivo em que são tomadas as decisões concretas sobre o desenvolvimento" (Lind 1995, p. 17 apud Alvarez 1998, p. 299). O que Alvarez sugere é que estar no Estado não necessariamente diminui o status de "militantes" dessas ativistas.

No Brasil, processos similares começaram a ocorrer no âmbito do movimento ambientalista muito antes do que no movimento de mulheres, talvez por conta da origem desse movimento em organizações científicas, o que levou a uma menor aversão à participação no governo na época da ditadura militar brasileira. O primeiro Secretário Nacional de 
Meio Ambiente, Paulo Nogueira Neto, que tomou posse em 1973, tinha sido previamente um ativista de uma organização conservacionista (Hochstetler e Keck 2007, p. 69). De acordo com Alonso et alli (2008), ativistas do movimento ambientalista se engajaram na criação de órgãos ambientais governamentais e, muitas vezes, quando conseguiam criá-los, ocuparam postos-chave, inclusive durante o regime autoritário. Vários órgãos ambientais, como, por exemplo, o Serviço Florestal do Ministério da Agricultura, foram ocupados por ambientalistas da Fundação Brasileira para Conservação da Natureza (Ibid, p. 27). A incorporação de ativistas no governo continuou no período mais recente. Por exemplo, no governo Lula, os dois ministros do Meio Ambiente (Marina Silva e Carlos Minc) tinham uma trajetória anterior de ativistas ${ }^{10}$.

A interpenetração de ativistas no Estado não é, entretanto, privilégio de "novos movimentos sociais", como o ambiental e o feminista. Esse fenômeno também ocorre entre ativistas da esquerda mais tradicional. Por exemplo, Feltran (2005) estudou as trajetórias de sete ativistas que, ao longo de 25 anos, passaram de participantes em movimentos populares para ocupar posições políticas no Estado e, em alguns casos, também no setor privado. A maioria engajou-se na política institucional por meio dos governos do Partido dos Trabalhadores, e, em especial, por meio do Orçamento Participativo. Feltran aponta ainda que todos mencionaram quão diferente era estar no governo (em comparação com atuar na sociedade civil). Como agentes do Estado, era necessário defender interesses sociais

10 Além disso, um dos mais importantes secretários no Ministério do Meio Ambiente durante o governo Lula, João Paulo Capobianco, havia sido fundador de uma das principais ONGs ambientalistas brasileiras (Hochstetler e Keck 2007, pp. 104-5). A prática de incorporar ativistas ambientais em postos altos do governo federal também ocorreu em governos anteriores. Fernando Collor nomeou José Lutzenberger, líder de uma das ONGs ambientalistas mais conhecidas, a AGAPAN, como Secretário Nacional do Meio Ambiente. O segundo mandato de Fernando Henrique Cardoso teve a participação de Mary Allegretti, uma ativista importante do movimento dos seringueiros da Amazônia das décadas de 1980 e 1990, como Secretária da Amazônia. 
mais amplos do que seria necessário como ativistas de movimentos específicos (Ibid, p. 400). Isso é necessariamente fonte de tensões e críticas daqueles que consideravam que os ocupantes de cargos não estavam fazendo o suficiente para defender os interesses dos movimentos sociais. Seja como for, Feltran, juntamente com Dagnino, Olvera e Panfichi (2006), argumenta que esses atores permanecem como parte de um "projeto" que cruza a fronteira entre Estado e sociedade civil. Apesar da participação no Estado implicar em riscos e exigir dos ativistas a defesa de interesses que não seriam necessariamente defendidos anteriormente, esses atores geralmente se dedicam a transformar o Estado no mesmo sentido que faziam antes, por exemplo, ao tentar promover políticas públicas socialmente justas, ou ao criar arenas participativas nas quais grupos da sociedade civil possam participar. Como sugere o segundo padrão mencionado anteriormente, a sobreposição de movimentos sociais e Estado não ocorre apenas por intermédio dessas transferências de recursos humanos. Alguns movimentos sociais parecem ter sido criados a partir de alianças entre indivíduos dentro e fora do Estado. Por exemplo, a importante reforma no sistema de saúde brasileiro nos anos 90 parece ter sido factível, de acordo com muitos pesquisadores (Doimo e Rodrigues, 2003; Gerschman, 1995; Mendes, 1994), devido à aliança entre dois movimentos originados na década de 1970. O Movimento Popular de Saúde (MOPS) era um movimento comunitário com raízes nos setores progressistas da Igreja Católica, que incluía freiras, padres, ativistas dedicados à educação popular, médicos da Pastoral da Saúde, profissionais da saúde vinculados ao novo sindicalismo e ativistas de comunidades que estavam demandando meIhorias nos serviços públicos de saúde e nas políticas de saneamento básico (Doimo e Rodrigues 2003, p. 2). O Movimento Sanitarista, por outro lado, era dominado pela "antiga esquerda" e, desde o início, privilegiou a crítica à preferência do regime militar pelos serviços privados de saúde. Seus membros incluíam profissionais da saúde, militantes partidários, 
professores e estudantes universitários, médicos vinculados a sindicatos e associações profissionais de saúde (Ibid, p. 3). Contudo, mesmo durante a ditadura militar, membros do Movimento Sanitarista tinham posições no governo, como argumentam Doimo e Rodrigues:

Em clara escalada hegemônica, passam a ocupar postos importantes dentro de aparatos estatais de saúde nas esferas federal, estadual e municipal, não sem buscar estabelecer interações com os movimentos organizados nos bairros. Mesmo ainda dentro do antigo MDB, a militância comunista já vinha ganhando algum espaço institucional desde a abertura lenta e gradual do governo Geisel (1974 a 1978). Conforme Castro (1992), diversos expoentes de Movimento Sanitarista já atuavam como técnicos do Ministério da Saúde, do Instituto de Pesquisas Aplicadas, quando são reativadas as Conferências Nacionais de Saúde mediante convocação por decretos ministeriais [nos anos 70] (Ibid, p.5).

Ao longo dos anos 80, esses dois movimentos começaram a unir forças. O interessante é que o Estado teve um papel importante, ao criar uma arena comum para que essa aliança pudesse ocorrer: as conferências nacionais que foram promovidas com apoio governamental por décadas começaram a incluir o movimento popular de saúde em meados da década de 1980. Nesses eventos, os dois grupos se puseram de acordo para a defesa do projeto central do movimento de saúde: a criação de um novo sistema público de saúde. O resultado final - o Sistema Único de Saúde - reflete as propostas de ambos os movimentos. Enquanto a criação de um sistema nacional e unificado provavelmente teve suas origens entre os profissionais de esquerda, os conselhos participativos que seriam criados nos anos 90 foram modelados a partir das experiências do movimento de saúde de São Paulo do final dos anos 70 (Sader, 1988; Avritzer, 2009).

A ação coletiva de atores cujos projetos ultrapassam a fronteira entre Estado e movimento também ocorre em contextos nos quais o Estado é governado por forças que se opõem ao movimento. Um exemplo mais 
recente pode ser encontrado na capital do país, que tem sido governada por forças conservadoras pela maior parte do seu período de autonomia política. O principal projeto político desses grupos é promover a expansão urbana, em grande parte em detrimento da proteção ambiental (Abers e Keck, 2009). Dado esse cenário, esperaria-se que o ativismo ambientalista em Brasília fosse pautado por uma forte dicotomia, contrapondo Estado e movimentos sociais. Porém, mesmo em Brasília é possível falar de ativismo ambientalista dentro e fora do Estado.

Como Pereira (2010) mostra, no seu estudo sobre a política ambiental da cidade, grupos da sociedade civil trabalham de forma próxima tanto com o Ministério Público como com o órgão ambiental local, o Instituto do Meio Ambiente e dos Recursos Hídricos (IBRAM). O Ministério Público é fundamental para transformar demandas da sociedade civil em demandas legais, com poder para mobilizar o sistema judiciário e assim pressionar os Poderes Executivo e Legislativo. Os promotores públicos estão em constante contato com ativistas da sociedade civil, especialmente aqueles que participam do Fórum de ONGs. Os vínculos também são fortes entre ativistas de movimentos sociais e o IBRAM. De fato, muitas vezes são os mesmos indivíduos: alguns burocratas são ativistas em organizações da sociedade civil, e o diretor da agência em 2010 havia sido, até pouco antes, um ativista cuja nomeação para o cargo foi aplaudida por muitas ONGs ambientalistas locais ${ }^{11}$.

Como devemos analisar esses vínculos entre Estado e movimentos sociais? Da perspectiva da vertente da "sociedade civil", o fato de associações criarem laços e trabalharem juntas em projetos com atores dentro do Estado é uma afronta ao conceito de "autolimitação". Ao fazerem isso, elas

11 É importante acrescentar, no entanto, que em momento posterior, quando o governo sofria intensas acusações de corrupção, o mesmo ator foi muito criticado por atores da sociedade civil porque não saiu do governo. 
abrem as portas para a colonização pela lógica do poder hierárquico do Estado. No entanto, descartar essas experiências não nos parece adequado. Como vários autores latino-americanos já sugeriram, tal rejeição a priori parece desconsiderar caminhos potencialmente frutíferos de democratização do Estado (Avritzer e Costa 2004; Dagnino, Olvera e Panfichi 2006).

Da perspectiva da política do conflito, essas relações colocam em xeque a presunção de que a relação entre Estado e movimentos sociais transformadores é sempre conflituosa. Nos casos anteriormente descritos, encontramos colaborações entre alguns atores dentro e fora do Estado, enquanto persistiram conflitos entre outros. Além disso, atores envolvidos ou até liderando subcomponentes do Estado (como o setor de meio ambiente ou de saúde) parecem atuar com uma certa autonomia em relação à hierarquia de poder, o que coloca em xeque qualquer visão homogeneizadora do Estado como contraponto dos movimentos sociais.

A próxima seção argumenta que a literatura recente sobre movimentos sociais e redes sugere alguns instrumentos que nos ajudam a mapear e analisar as relações entre atores estatais e não estatais descritas anteriormente.

\section{De Movimentos Sociais a Redes de Ativistas?}

Em paralelo aos debates propostos pelos teóricos da sociedade civil e da política do conflito, ganhou importância, ao longo dos anos 90, uma literatura que busca analisar movimentos sociais em termos de redes de atores $^{12}$. Ao contrário das outras abordagens, entretanto, essa literatura

12 Apesar de ter ganhado maior disseminação na literatura sobre movimentos sociais apenas nas últimas duas décadas, a associação entre "redes" e ação coletiva não é nova. O sociólogo alemão Georg Simmel já afirmava, em 1922, que os indivíduos possuem tanto filiações primárias, ou seja, aquelas com as quais nós nascemos e que independem da nossa vontade, como secundárias, aquelas que são por nós livremente escolhidas. As primeiras, ele denominava causas orgânicas ou naturais da ação coletiva e as segundas, ele denominava causas racionais. Segundo Simmel, o padrão de vinculação da era moderna se diferenciaria do predominante 
não oferece uma terminologia unificadora alternativa, como "sociedade civil" ou "política do conflito". Para boa parte dos autores cujas ideias resenhamos a seguir, a análise baseada em redes questiona se é possível estabelecer, a priori, as fronteiras do conjunto de atores envolvidos na ação coletiva e, portanto, as fronteiras da nossa unidade de análise.

O uso do termo "redes" associado a definições de movimentos sociais tem, porém, uma história que precede a década de 1990. Para Curtis e Zurcher (1973), por exemplo, movimentos sociais formam campos multiorganizacionais amplos, baseados em redes que são estabelecidas por vínculos entre organizações e/ou entre indivíduos. Por sua vez, Alberto Melucci vinculou a ideia de redes à sua visão teórica sobre os "novos movimentos sociais", utilizando o conceito para descrever o surgimento de novas formas de organização da ação coletiva. Estas se diferenciariam, por exemplo, das organizações sindicais tradicionais - caracterizadas por rígidas hierarquias organizacionais - pela formação de unidades diversificadas e autônomas, as quais se manteriam em contato por meio de redes de comunicação (1996, p. 113). Para esse autor, é inútil procurar fronteiras claras para os novos movimentos sociais, cujas formas "resemble an amorphous nebula of indistinct shape and with variable density" (Ibid, p. 114). Uma visão desses movimentos como redes permitiria compreender melhor as mudanças na dinâmica interna da ação coletiva. Em especial, possibilitaria analisar como os atores lidam com o persistente dilema da reconciliação entre suas aspirações por autonomia e as necessidades de coordenação interna e representação dos movimentos sociais (Ibid, p. 344-347).

Em 1992, em um artigo que fazia uma revisão de várias definições de movimentos sociais, Mario Diani ressaltou três aspectos em comum na lite-

na Idade Média porque o indivíduo passa a poder se filiar a uma multiplicidade de grupos, em combinações infinitas que tornam a análise de redes um enorme desafio metodológico para os cientistas sociais (Simmel 1922 [1955]). 
ratura: movimentos sociais seriam (1) uma rede de interações informais entre indivíduos e organizações que (2) se orientam de forma conflituosa em relação a um adversário definido e (3) têm uma identidade compartilhada (Diani, 1992). Nessa definição, portanto, redes de interações só podem ser caracterizadas como movimentos sociais na medida em que existe, ao mesmo tempo, orientação conflituosa e formação de identidade coletiva.

Mais recentemente, a forte disseminação do uso do conceito de "redes" tem tido como resultado um conjunto heterogêneo de análises. Parte desses estudos sofre de dois problemas: uma visão aprioristicamente positiva das redes como metáfora para descrever novas formas de organização coletiva, supostamente menos hierárquicas ${ }^{13}$, e uma visão teoricamente pouco desenvolvida de redes que não especifica os vínculos entre os diferentes tipos de atores.

Para compreender em que medida esta literatura pode nos ajudar a analisar as imbricações entre movimentos sociais e o Estado, é interessante discutir especificamente o segundo problema. Parte dos estudos sobre redes argumenta que elas incluem não apenas movimentos sociais, mas também ONGs, acadêmicos, governos e organizações internacionais. É o caso, por exemplo, do estudo de Elizabeth Umlas (1998) sobre a criação de uma rede ambientalista no México, o Comitê Nacional para

13 Para os autores que utilizam o conceito para descrever uma tendência geral em direção a movimentos sociais menos hierárquicos e mais flexíveis, redes são formas de organização que representam "a superior social morphology for all human action" (Castells 2000, p. 15) e estão tornando-se "a signature element of global organizing" (Anheier e Themudo 2002, p. 191). Essa compreensão é, aliás, similar à maneira como os próprios ativistas têm utilizado o termo no seu cotidiano, muitas vezes dando o nome de "rede" a coalizões heterogêneas como forma de enfatizar sua horizontalidade, flexibilidade e democracia interna. No entanto, essa visão positiva das redes tem sido criticada por negligenciar as relações de poder entre os atores. Não ajudaria, portanto, a compreender o dilema entre autonomia e coordenação apontado por Melucci. Para esses críticos, se as redes sociais construídas pelos atores são ou não hierárquicas é uma questão empírica, a ser analisada e não tomada como um dado da realidade (e.g., Mische 2003, p. 260; von Bülow 2010, esp. capítulos 1 e 2). 
a Defesa dos Chimalapas, o qual reúne ONGs ambientalistas, artistas, intelectuais, militantes, pesquisadores e representantes de comunidades indígenas com o objetivo comum de evitar a construção de uma rodovia que cruzaria uma reserva ambiental e terras indígenas. Também podemos citar o estudo de Margaret Keck e Kathryn Sikkink (1998) sobre redes transnacionais de defesa de direitos (denominadas por elas de advocacy networks), formadas por atores que vão desde organizações da sociedade civil até jornalistas e integrantes de governos e organismos internacionais que atuam transnacionalmente em uma área temática específica. Em ambos os casos, as fronteiras das redes são definidas com base em ações e valores comuns que reúnem indivíduos de diferentes instituições. Ou seja, apesar de incluir atores normalmente não identificados como parte de movimentos sociais, essas redes parecem cumprir os três critérios propostos por Diani (1992) interações informais, ações em comum em torno de conflitos políticos ou culturais e identidade coletiva.

À medida que tem crescido o interesse em adotar a rede como unidade de análise, um conjunto de autores tem procurado apresentar os dados sobre interações de modo mais sistemático, a partir da utilização de técnicas de análise de redes que permitem mapear formalmente os vínculos entre os atores.

No seu estudo sobre redes ambientalistas na Itália, Mario Diani (1995) privilegiou a delimitação das fronteiras da rede a partir das definições dos próprios atores sobre as suas identidades, incluindo todos aqueles grupos que se declararam partícipes do movimento ambientalista e que foram reconhecidos por outros atores como tais. Essas informações foram colhidas por meio de entrevistas semiestruturadas com líderes de organizações ambientalistas e com militantes. Tendo como base uma identidade comum, o autor estudou quatro tipos possíveis de vínculos: a promoção conjunta de campanhas; o intercâmbio regular de informações; a participação de 
membros importantes simultaneamente em mais de uma organização e a existência de laços de amizade entre membros importantes de diferentes organizações. Os dois primeiros tipos de vínculos formaram a "rede visível" ou "formal" do movimento ambientalista; os dois últimos tipos formaram a "rede latente" ou "submersa", enfatizada por Melucci.

Em um estudo mais recente sobre o movimento ambientalista na região de Londres, Clare Saunders também aplicou um questionário a organizações ambientalistas. A autora partiu da definição de movimento social proposta por Diani em 1992, mas argumentou que a ênfase do autor em "interações informais" poderia levar a incluir em um movimento social organizações ou indivíduos que, na prática, não compartilham nada entre si. Por exemplo, a identificação de laços de amizade entre membros de organizações ambientalistas não permitiria falar da existência de um movimento social. Da mesma forma, eventuais trocas de informação entre organizações não levaria a um vínculo identitário suficientemente forte (Saunders 2007, p. 238). O problema foi evitado, para Saunders, ao incluir perguntas sobre vínculos baseados em atividades de colaboração (Idem, p. 239). Redes só são movimentos sociais, nessa perspectiva, na medida em que são constituídas por vínculos identitários baseados em colaboração.

Esses exemplos buscam responder à pergunta sobre quais são os conteúdos dos vínculos que permitem que delimitemos as fronteiras dos movimentos sociais. Em parte, a dificuldade para respondê-la tem a ver com o fato de que os vínculos baseados em identidades e em ações são dinâmicos. Nós argumentamos neste artigo que parte do desafio também tem a ver com o fato de que esses vínculos podem cruzar as fronteiras entre sociedade e Estado. Nesse sentido, embora a literatura citada anteriormente tenda a enfocar atores fora do Estado, os critérios delimitados tanto por Diani como por Saunders não excluem automaticamente atores estatais. Além disso, o debate sobre vínculos sugere alguns instrumentos 
que nos ajudam a mapear ações de colaboração (e não só de conflito) entre atores posicionados em diferentes organizações. Autores como Diani, Mische e Saunders concordam que as redes que formam movimentos sociais não são dadas pela estrutura social, mas são criadas a partir de escolhas dos atores. Os vínculos existentes são, assim, carregados de significados (White, 1992) que possibilitam que os atores se reconheçam como parte de uma mesma ação.

Alguns autores que trabalham nesta perspectiva propõem a volta ao conceito de movimento social, sem, no entanto, deixar de preocupar-se sobre como diferenciar movimentos sociais de outros tipos de ação coletiva. O trabalho mais recente de Diani e Bison ([2004] 2010) dá algumas pistas adicionais nesse sentido. A partir de uma análise de redes de organizações que se mobilizam sobre diferentes temas em duas cidades inglesas, os autores propõem uma diferenciação entre seis tipos de "processos de ação coletiva": organizações de consenso, organizações de conflito, coalizões de consenso, coalizões de conflito, movimentos de consenso e movimentos sociais. Esses tipos variam de acordo com três variáveis dicotômicas: presença ou ausência de orientação para o conflito, com adversários claramente identificados; trocas informais densas ou esparsas entre indivíduos ou organizações; e identidade coletiva fraca ou forte (Idem, p. 221). Para ser um movimento social, a rede deve ser baseada em vínculos informais densos, uma identidade forte e um conflito claro com alvos específicos. Ação coletiva sem esse caráter conflitivo torna-se um "movimento de consenso" ou uma "coalizão de consenso"; ação coletiva sem uma identidade forte pode ser uma coalizão (de conflito ou de consenso) ou uma organização (também de conflito ou de consenso).

A tipologia oferecida por Diani e Bison pode nos ajudar a distinguir entre diferentes processos de ação coletiva que conectam atores dentro e fora do Estado. À medida que os membros de uma rede passem a ter objetivos 
mais moderados, podem vir a pressionar um movimento social para tornar-se um "movimento de consenso". Por outro lado, à medida que lutam por criar espaços no Estado que se contrapõem a práticas tradicionais ou se opõem a grupos particulares (como parece ser, muitas vezes, o caso de atores em órgãos que cuidam da proteção do meio ambiente), talvez devêssemos aceitar esses vínculos e práticas como parte de um movimento social.

\section{Comentários Finais: movimentos sociais dentro do Estado?}

A literatura recente sobre ação coletiva, em especial a abordagem sobre sociedade civil inspirada em Habermas e a abordagem da dinâmica do conflito, representada pelo livro Dynamics of Contention, sugere que é preciso ir além do estudo sobre o que tradicionalmente entendemos por movimentos sociais. Preocupados com a construção de uma esfera pública livre e democrática, os defensores do conceito de sociedade civil argumentam que uma multiplicidade de tipos de grupos e associações deveria ser considerada. Preocupados com as interações entre múltiplas formas de conflitos sociais, os defensores da política do conflito sustentam que diferentes modalidades de ação coletiva precisam ser incluídas na nossa agenda de pesquisa. No entanto, aqueles que adotam o conceito normativo de sociedade civil são criticados por minimizar a relevância de grupos que fazem a mediação entre esta e o mercado e o Estado (Warren 2002) e por ignorar a importância de se transformar também o Estado (Avritzer e Costa 2004). Por sua vez, os defensores da política do conflito são criticados por ignorar o ativismo que não tem o Estado como alvo ou como participante (Rucht 2003; Taylor, 2003) e por limitar as relações de movimentos transformadores com o Estado a relações de confrontação.

Nós concordamos com essas críticas, mas vamos além: essas abordagens não são úteis para compreender as múltiplas formas de intersec- 
ção entre movimentos sociais e o Estado. Nesse sentido, não só é relevante teorizar sobre como os movimentos sociais constroem vínculos de colaboração com o Estado, mas também deveríamos compreender como, às vezes, movimentos sociais buscam alcançar seus objetivos trabalhando a partir de dentro do aparato estatal.

O desafio metodológico, é claro, é mapear e analisar as redes que conectam atores de movimentos sociais com atores estatais, de tal forma que possamos verificar se indivíduos que ocupam cargos no Estado podem ser incluídos como "membros" de um movimento. A coleta sistemática de dados sobre os tipos de laços entre atores estatais e não estatais de diferentes movimentos sociais, e como esses laços se transformam ao longo do tempo, é um esforço de pesquisa que ainda está por ser realizado. Somente a partir de tal esforço poderemos entender em quais condições os vínculos identitários e os compromissos coletivos sobrevivem (ou não) à mudança de posição dos atores que ingressam na esfera estatal.

Contudo, devemos evitar a inclusão acrítica de atores estatais na nossa agenda de pesquisa. Uma vez que se tornam parte do Estado, os indivíduos precisam prestar contas das suas ações a interesses e atores que vão além do movimento social ao qual pertencem. Estão inseridos em uma hierarquia que limita a sua autonomia e que submete suas ações ao poder de veto de atores com uma lógica distinta, em especial a lógica da política partidária e da criação de coalizões de governo. O resultado pode ser que, ao entrar para o aparato estatal, ativistas de movimentos sociais passem a defender posições mais moderadas ou até contrárias à missão do movimento.

É importante lembrar que tais problemas são parecidos com aqueles que têm sido longamente debatidos pelas teorias dos movimentos sociais quando se trata dos riscos de organização formal na própria sociedade civil. A partir da noção da Lei de Ferro da Oligarquia de Michels, Piven e Cloward (1979) constataram que grandes organizações de movimento social , frequentemente, se tornam fins em si mesmas, distanciando-se das 
suas missões originais. Nesses casos, os ativistas tornam-se dependentes da continuidade das organizações para a sua sobrevivência pessoal e, assim, tendem a torná-la mais moderada. Deveríamos, então, automaticamente excluir esse tipo de ator do nosso campo de análise? Qual é a diferença entre esse tipo de participação e a participação em instituições estatais?

A possibilidade de "desqualificar" alguns atores a partir da sua posição organizacional nos remete a uma das razões pelas quais é interessante pensar de forma mais ampla sobre o campo de estudo dos movimentos sociais: no passado, a imposição de definições externas sobre o que deveria "contar" como um movimento social cegou os estudiosos de formas de ação coletiva que se opunham ao status quo, mas que não se conformavam com definições aceitas de transformação social. Apesar da ênfase nos "novos movimentos sociais", entre as décadas de 1960 e 1980 muita energia ainda era direcionada para a discussão sobre quais movimentos eram legítimos, realmente transformadores, ou relevantes socialmente. Esse debate refletia ainda a influência do marxismo, de modo relativamente explícito. Entretanto, a transição para o pós-marxismo e para os estudos multiculturais tem se baseado, em boa medida, no reconhecimento dos perigos da exclusão de certos tipos de ação social. O caso clássico é o das feministas que tentavam trabalhar a partir dos movimentos socialistas, cuja causa era vista como um "epifenômeno".

A agenda de pesquisa que propomos, portanto, começa com o reconhecimento de que redes de movimento social podem, teoricamente, ultrapassar as fronteiras entre sociedade e Estado. Essa hipótese poderá ser confirmada a partir da coleta de dados sobre diferentes tipos de vínculos entre movimentos sociais e Estado, do estudo de trajetórias de indivíduos que cruzam as fronteiras entre o ativismo fora e dentro do Estado e da análise sobre como esses cruzamentos impactam tanto os movimentos sociais como o Estado. 


\section{Social movements in theory and practice: how to study activism across State-society boundary?}

\section{Abstract}

In the last two decades, social movement scholars have brought the frontiers of the field into question. Some have advocated for the substitution of "social movements" for "civil society", while others have proposed to rename the field as the study of "contentious politics". In both of these cases, the justification is that the field of social movements has become too narrow, empirically as well as theoretically. The article discusses these reformist initiatives and identifies a problem they have in common: the lack of attention to numerous forms of interaction between actors involved with social movements situated both outside and inside the state. We offer a theoretical discussion based on the results of empirical research undertaken in Brazil on this issue, which, we argue, help us better understand the relationship between states and social movements. We also argue that the recent literature on social networks provides analytical clues to think about activism from within state structures.

Keywords: Social movements. State. Participation. Civil society. Contentious politics.

\section{Referências}

ABERS, Rebecca; KECK, Margaret. Mobilizing the state: the erratic partner in Brazil's participatory water policy. Politics \& Society, vol. 37, n. 2, p. 289-314, 2009.

ALONSO, Angela. As Teorias dos Movimentos Sociais: um balanço do debate". Lua Nova, 76, p. 49-86, 2009.

ALONSO, Angela; COSTA, Valeriano; MACIEL, Débora. Identidade e estratégia na formação do movimento ambientalista brasileiro. Novos Estudos CEBRAP, vol. 4, n. 70, p. 151-167, 2008.

ANHEIER, Helmut; THEMUDO, Nuno. 2002. Organisational forms of global civil society: implications of going global. In: ANHEIER, Helmut; THEMUDO, Nuno (Orgs.). Global Civil Society 2002. Oxford: Oxford University Press. p. 191-216.

ARATO, Andrew; COHEN, Jean. Sociedade civil e Teoria Social. In: AVRITZER, Leonardo (org.). Sociedade Civil e Democratização. Belo Horizonte: Del Rey, 1994. p. 147-192. 
ALVAREZ, Sonia E.. A 'Globalização' dos Feminismos Latino-Americanos. Tendências dos Anos 90 e desafios para o novo milênio. In: ALVAREZ, Sonia; DAGNINO, Evelina; ARTURO, Escobar. Cultura e Política nos Movimentos Sociais Latinoamericanos. Novas Leituras. Belo Horizonte: UFMG, 1998. p. 383-426.

ALVAREZ, Sonia; ESCOBAR, Arturo. Conclusion: Theoretical and Political Horizons of Change in Contemporary latin American Social Movements. In: ESCOBAR, Arturo; ALVAREZ, Sonia. The Making of Social Movements in Latin America. Boulder, CO: Westview Press, 1992. p. 317-329.

AVRITZER, Leonardo. Participatory Institutions in Democratic Brazil. Baltimore: The Johns Hopkins University Press, 2009.

AVRITZER, Leonardo; COSTA, Sérgio. Teoria crítica, democracia e esfera pública: concepções e usos na América Latina. Dados - Revista de Ciências Sociais, vol. 47, n. 4, p. 703-728, 2004.

CASTELLS, Manuel. Toward a sociology of the network society. Contemporary Sociology, vol. 29, n.5, p. 693-699, 2000.

CHAMBERS, Simone. A Critical Theory of Civil Society, In: CHAMBERS, Simone; KYMLICKA, Will. Alternative Conceptions of Civil Society. Princeton e Oxford: Princeton University Press, 2002. p. 90-112.

COHEN, Jean L.; ARATO, Andrew. Civil Society and Political Theory. Cambridge, Ma: MIT, 1992.

CURTIS, Russell L.; ZURCHER, Louis A. Stable resources of protest movements: the multi-organizational field. Social Forces, 52, p. 53-61, 1973.

DELLA PORTA, Donatella; DIANI, Mario. Social movements: An Introduction. Malden, MA: Blackwell Publishing, 2006.

DIANI, Mario. The Concept of Social Movement. The Sociological Review 40, p. 1-25, 1992.

DIANI, Mario. Green Networks. A Structural Analysis of the Italian Environmental Movement. Edinburgh: Edinburgh University Press, 1995.

DIANI, Mario. The Terrestrial Emporium of Contentious Knowledge. Mobilization, vol. 8, n. 1. (Mobilization Book Symposium, Dynamics of Contention), p. 109-112, 2003.

DIANI, Mario; BISON, Ivano. Organizações, coalizões e movimentos, Revista Brasileira de Ciência Política, núm. 3, p. 220-249, 2010 [2004].

DOIMO, Ana Maria. A Vez e a Voz do Popular: movimentos sociais e participação política no Brasil pós-70. Rio de Janeiro: Relume Dumará, 1995. 
DOIMO, Ana Maria; RODRIGUES, Marta. A formulação da nova política de saúde no Brasil em tempos de democratização: entre uma conduta estatista e uma concepção societal da atuação política. Política e Sociedade, vol. 2, n. 3, p. 95-115, 2003.

ESCOBAR, Arturo. Culture, Economics, and Politics in Latin American Social Movements Theory and Research. In: ESCOBAR, Arturo; ALVAREZ, Sonia. The Making of Social Movements in Latin America. Boulder, CO: Westview Press, 1992.

ESCOBAR, Arturo; ALVAREZ, Sonia. The Making of Social Movements in Latin America. Boulder. CO: Westview Press, 1992.

FELTRAN, Gabriel. Desvelar a política na periferia: histórias de movimentos sociais em São Paulo. São Paulo: Associação Editorial Humanitas, 2005.

FRANK, André Gunder; FUENTES, Marta. Dez teses acerca dos movimentos sociais. Lua Nova. n. 17, p. 29-48. Junho 1989.

FRASER, Nancy. Rethinking the Public Sphere: A Contribution to the Critique of Actually Existing Democracy. In: CALHOUN, Craig (org.). Habermas and the Public Sphere. Cambridge, MIT Press, 1992. p. 109-142.

GERSCHMAN, Sílvia. 1995. A democracia Inconclusa. Um estudo da Reforma Sanitária Brasileira. Rio de Janeiro: Fiocruz, 1995.

GOODWIN, Jeff; JASPER, James M. Caught in a Winding, Snarling Vine: The Structural Bias of Political Process Theory. Sociological Forum, vol. 14, n. 1, p. 27-54, 1999.

HABERMAS, Jürgen. Theory of Communicative Action. Boston: Beacon Press, 1984.

HABERMAS, Jürgen. The Structural Transformation of the Public Sphere. Cambridge, MA: MIT Press, 1989 [1962].

HABERMAS, Jürgen. Direito e Democracia, Entre Facticidade e Validade. Tempo Brasileiro, 2003.

HOCHSTETLER, Kathryn; KECK, Margaret. Greening Brazil: environmental activism in state and society. Durham: Duke University Press, 2007.

KECK, Margaret E.; SIKKINK, Kathryn. Activists beyond Borders: Transnational Advocacy Networks in International Politics. Ithaca: Cornell University Press, 1998.

KOOPMANS, Ruud. 2003. A Failed Revolution - But a Worthy Cause. Mobilization, vol. 8, n. 1, (Mobilization Book Symposium, Dynamics of Contention), p. 116-119, 2003. 
JASPER, James.. Chapter 1: After the Big Paradigms: Social Movement Theory Today, 2009. Trabalho apresentado em Politics and Protest Workshop, CUNY Graduate Center, 5 de fevereiro de 2009. Disponível em: <http://www.jamesmjasper.org/Spring2009Schedule.html> .

LISBOA, Armando de Melo. Economia Solidária: incubando uma outra sociedade. Proposta, 97, junho-agosto, p. 50-58, 2003.

McADAM, Doug. 2003. 'Eehh, What's Up (with) DOC?' Clarifying the Program. Mobilization, vol. 8, n. 1, (Mobilization Book Symposium, Dynamics of Contention), p. 126-134, 2003.

MCADAM, Doug; TARROW, Sidney; TILLY, Charles. Dynamics of Contention. Cambridge: Cambridge University Press, 2001.

MELUCCl, Alberto. A Invenção do Presente. Petrópolis: Ed. Vozes, 1991 [1982].

$\overline{17, \text { p. 49-66, }} 1989$.

. Um objetivo para os movimentos sociais? Lua Nova, Junho 89, No.

. Challenging Codes: Collective action in the information age. Cambridge: Cambridge University Press, 1996.

MENDES, Eugênio (Org). Distrito sanitário: o processo social de mudança das práticas sanitárias do Sistema Único de Saúde. Rio de Janeiro/São Paulo: Abrasco/ Hucitec, 1994.

MISCHE, Ann. Cross-talk in movements: reconceiving the culture-network link. In: DIANI, Mario; McADAM, Doug (Orgs.). Social Movements and Networks: relational approaches to collective action. Oxford: Oxford University Press, 2003. p. 258-280.

OLIVEIRA, Marta Maria Gomes de. ONGs, Meio Ambiente e Regióes. Mimeo. 2009.

OLIVER, Pamela E. Mechanisms of Contention. Mobilization, vol. 8, n. 1, (Mobilization Book Symposium, Dynamics of Contention), 2003. p. 119-122.

PHILLIPS, Anne. Feminism and Civil Society. In: CHAMBERS, Simone; KYMLICKA, Will. Alternative Conceptions of Civil Society. Princeton e Oxford: Princeton University Press, 2002. p. 71-89.

PIVEN, Frances Fox; CLOWARD, Richard. Poor People's Movements. New York, Vintage, 1979.

RUCHT, Dieter. 2003. Overcoming the "Classical Model?" Mobilization, vol. 8, n. 1,. (Mobilization Book Symposium, Dynamics of Contention), p. 112-116, 2003.

SAUNDERS, Clare. Using social network analysis to explore social movements: a relational approach. Social Movements, vol. 6, n. 3, p. 227-243, 2007. 
SCHEHR, Robert C. Dynamic Utopia: Establishing intentional communities as a new social movement. Westport, CT: Bergin and Garvey, 1997.

SCHERER WARREN, Ilse. O Caráter dos Movimentos Sociais. In: SCHERER WARREN, Ilse; KRISCHKE, Paulo J. (Orgs.) Uma Revolução no Cotidiano? Os novos movimentos sociais na América Latina. São Paulo: Editora Brasiliense, 1987. p. 35-51.

SIMMEL, Georg. Conflict and the web of group affiliations. Glencoe: Free Press, 1922 [1955].

TARROW, Sidney. Poder em Movimento. Petrópolis: Vozes, 2009 [1994].

TAYLOR, Verta. Plus ça change, /çlus c'est la même chose. Mobilization, vol. 8, n. 1, 2003. (Mobilization Book Symposium, Dynamics of Contention) p. 122-126, 2003.

TOURAINE, Alain. The voice and the eye - an analysis of social movements. Cambridge: Cambridge Univ. Press, 1981.

TOURAINE, Alain. Podemos Viver Juntos? Iguais e Diferentes. Petrópolis: Editora Vozes, 1999.

VON BÜLOW, Marisa. Building transnational networks: civil society and the politics of trade in the Americas. Cambridge: Cambridge University Press, 2010.

WALZER, Michael. The Concept of Civil Society. In: WALZER, M. (Org.). Toward a Global Civil Society. Providence e Oxford: Berghahn Books, 1998.

WARREN, Mark E. Democracy and Association. Princeton: Princeton University Press, 2001.

WHITE, Harrison. Identity and Control: a structural theory of social action. Princeton, Princeton University Press, 1992.

Recebido em: 04/05/2011

Aceite final: 14/07/2011 